\title{
Bone metastases in children presenting with renal tumours
}

\author{
W. LAWLER AND H. B. MARSDEN \\ From the Department of Pathology, Mancheser University, UK
}

SUMMARY A survey of bone metastases in 132 children presenting with renal tumours has been carried out using material from the Manchester (England) Children's Tumour Registry during the period 1954 to 1976. Seven such cases were found. Only one of the 117 Wilms' tumours developed bone metastases. The remainder included carcinoma (1/4), 'bone metastasising renal tumour of childhood' $(2 / 3)$, atypical tumours $(2 / 2)$, and lymphosarcoma (1/1). Bone metastases from true nephroblastoma seem to be an exceptional finding.

Bone metastases are uncommon in children presenting with renal tumours. An analysis of such cases, verified histologically, in the Manchester Children's Tumour Registry (CTR) during the period 1954 to 1976 inclusive is shown in the accompanying table.

Table Total number of children presenting with renal tumours in the Manchester Children's Tumour Registry (1954-76) and number of cases with bone metastases

\begin{tabular}{lcl}
\hline Pathological diagnosis & $\begin{array}{l}\text { Total no. of } \\
\text { cases }\end{array}$ & $\begin{array}{l}\text { Cases with bone } \\
\text { metastases }\end{array}$ \\
\hline Wilms' tumour & 117 & 1 \\
$\begin{array}{l}\text { Hypernephroma } \\
\text { Mesoblastic nephroma }\end{array}$ & 4 & 1 \\
'Bone metastasising renal tumour of & 3 & 0 \\
childhood' & 3 & 2 \\
$\begin{array}{l}\text { Atypical tumours } \\
\text { Lymphosarcoma }\end{array}$ & 2 & 2 \\
Unclassifiable (lack of adequate & 1 & 1 \\
material) & 2 & 0 \\
Total & 132 & 7 \\
\hline
\end{tabular}

Clinical and pathological features

CASE 1

DCMR (CTR 40/55) May 1955. A boy aged 4 years and 10 months presented with haematuria. No abdominal mass was palpable. Intravenous and retrograde pyelography showed enlargement of the left kidney, hydronephrosis, and a filling defect in the pelvis and upper calyx. At laparotomy there was a tumour of the upper pole of the left kidney with a papillary growth ulcerating into the upper calyx and pelvis. Nephrectomy was carried out, and radiotherapy was given. Five months later there was

Received for publication 23 November 1978 evidence of metastases in both lung fields. These responded to $x$-ray therapy but a shadow persisted in the left lung, and one year later segmental resection of the left lower lobe was performed. There was a $2 \mathrm{~cm}$ diameter metastasis at the apex of this lobe, and a smaller subpleural nodule. During the following months the child developed bone pain and began to limp. $X$-rays showed metastases in the pelvis, femora, and left tibia. He died two years after diagnosis. Necropsy was not carried out.

\section{Pathology}

The renal tumour was a typical nephroblastoma with blastema, loose mesenchyme, and moderate tubular differentiation. The metastasis at the apex of the left lower lobe had a similar appearance; the subpleural nodule consisted of striated muscle only.

\section{CASE 2}

PB (CTR 122/70) November 1970. A boy aged 11 years presented with haematuria and loss of weight. A mobile mass was palpable in the right paraumbilical region. At laparotomy a tumour was found involving the medial aspect of the lower pole of the right kidney. There were many enlarged lymph nodes. Nephrectomy was performed together with excision of the hilar nodes; none of the para-aortic nodes could be removed. Radiotherapy was given with vincristine followed by actinomycin $D$. Six months later there was pain in the lumbar spine, and an $x$-ray showed bony destruction; radiotherapy was given. He subsequently developed enlargement of the liver, and a metastasis appeared in the left lung. The patient died 17 months after diagnosis. There was no necropsy. 


\section{Pathology}

The tumour was $7 \times 6 \times 6 \mathrm{~cm}$ in size, lobular, white, and firm, with a small blood-filled cyst. There were also small outlying nodules. Microscopically the appearances were typical of a clear cell primary renal carcinoma with extensive lymph node involvement.

\section{CASE 3}

MF (CTR 100/70) October 1970. A boy aged 1 year 11 months presented with two episodes of haematuria in the preceding six weeks. He had become feverish and irritable with loss of appetite and weakness of the legs. Flexion of the right hip was limited, and there was a palpable mass on the right side of the abdomen. Intravenous and retrograde pyelography showed right hydronephrosis with distortion of the renal outline. At operation a tumour of the upper pole of the right kidney was found, and nephrectomy was performed. No enlarged lymph nodes were noted. Radiotherapy and actinomycin $\mathrm{D}$ were given. Two weeks later a lytic lesion was found in the shaft of the left femur with periosteal reaction. Chest $x$ rays were normal. There was limitation of movement of the cervical spine, although no metastases were detected on $x$-ray. The child deteriorated and died with widespread metastases, the clinical course being six months. No necropsy was carried out.

\section{Pathology}

The kidney had a tumour mass $10 \times 8 \times 7 \mathrm{~cm}$ at the upper pole. The capsule was intact. The cut surface was solid and grey-white with one area of necrosis. The ureter, major vessels, and lymph nodes were not involved. On microscopy there was a prominent capillary pattern throughout, and rounded, ovoid, or polygonal tumour cells, $10-18 \mu$ in size, with a delicate chromatin pattern were present (Fig. 1). Occasional tubules lined by cuboidal epithelium were seen at the periphery of the tumour. The appearances were unlike those of a Wilms' tumour, and the neoplasm was regarded as a 'bone metastasising renal tumour of childhood', more detailed descriptions of which have been given elsewhere (Marsden and Lawler, 1978; Marsden et al., 1978).

\section{CASE 4}

SMR (CTR 139/70) December 1970. An asymptomatic boy aged 1 year 11 months but abdominal enlargement over a period of several months had been noticed by the father. On examination a mass

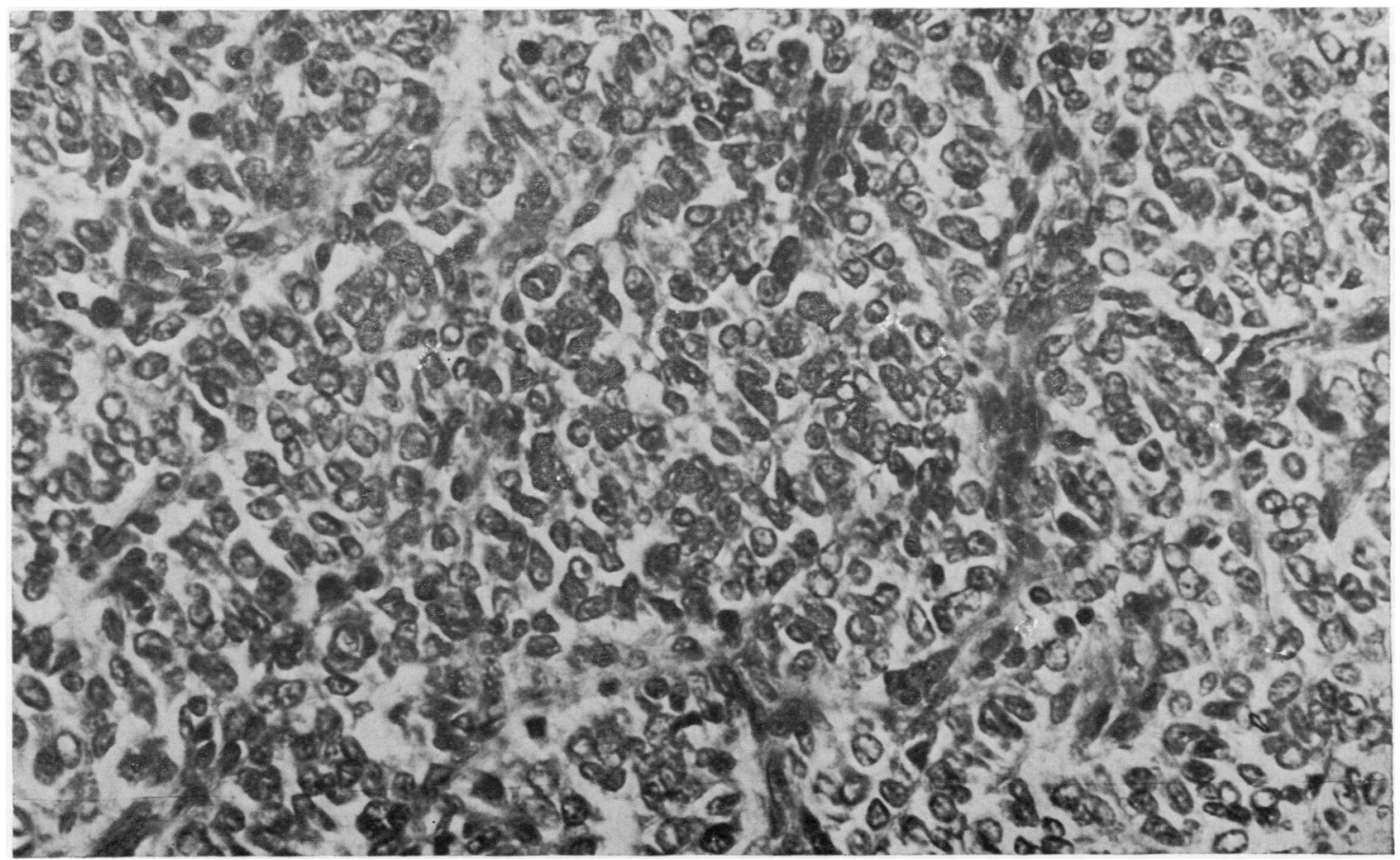

Fig. 1 Case 3. 'Bone metastasising renal tumour of childhood' showing a prominent capillary pattern and tumour cells with delicate chromatin. 
was palpable in the right hypochondrium, extending to the pelvic brim and across the midline. Catecholamine levels and $x$-rays of the chest and skeleton were normal. Intravenous pyelography showed distortion and displacement of the renal outline, and a renal aortogram indicated a tumour in the lower two-thirds of the right kidney. At operation a large tumour was found, and nephrectomy was carried out together with removal of two enlarged hilar lymph nodes. Radiotherapy and actinomycin $\mathbf{D}$ were given. Seven months later there was swelling of the right zygoma and weakness of the right leg. $X$-rays showed destruction of the right malar bone and evidence of metastases in the right femur with a pathological fracture. He was treated with radiotherapy but died after a clinical course of 13 months. Metastases developed in the vault of the skull, both scapulae, ribs, sternum, clavicle, vertebrae, pelvis, both femora, both humeri, right ulna, and left tibia. Deposits were also noted in both lung fields. There was no necropsy.

\section{Pathology}

The kidney had a tumour $17 \times 13 \times 8 \mathrm{~cm}$ in its lower pole. The capsule was intact, and the renal vein and the double renal pelvis were not involved. The cut surfaces were buff-white and uniform, a few small cysts containing clear fluid. Microscopy showed the appearances of a bone metastasising renal tumour of childhood' similar to those in case 3. The lymph nodes contained metastatic tumour.

\section{CASE 5}

CHN (CTR 114/57) August 1957. A coloured boy aged 4 years, born in Kingston, Jamaica, presented on account of intermittent attacks of vague abdominal pain over a period of approximately 18 months. His abdomen had been rather swollen. A mass was palpable in the left hypochondrium, and intravenous pyelography showed deformity of the calyceal pattern on the left side. Chest $x$-rays were normal. At operation a tumour of the lower two-thirds of the left kidney was found. Nephrectomy was carried out together with removal of enlarged para-aortic lymph nodes. Radiotherapy was given. Sixteen months later the patient developed VI and VII cranial nerve palsies. Palpable masses were present over the frontal region, and $x$-rays showed widespread skull metastases. These were controlled by radiotherapy, but a lytic lesion developed in the right femur followed by pathological fractures in the right femur and the left humerus. There was a good response to radiotherapy, but the child died from bronchopneumonia after a clinical course of four and a half years. There was no necropsy.

\section{Pathology}

Macroscopic examination showed a firm, creamcoloured tumour, $11 \mathrm{~cm}$ in maximum diameter, with some lobulation and thin fibrous trabeculae. There were small cystic areas up to $1.5 \mathrm{~cm}$ in diameter. The tumour was in the lower pole of the kidney and had a narrow covering of renal tissue. The remaining pelvis and calyces showed moderate dilatation. The lymph nodes were enlarged, matted together, and replaced by tissue similar to that of the main tumour. Microscopic examination showed a rather varied appearance. The greater part of the tumour consisted of narrow clefts or spaces lined by small cells. A number of these spaces contained red blood corpuscles. Closely packed, intervening, fibrous septa were a prominent feature. Tubules lined by cuboidal epithelium were also present (Fig. 2). In addition, there was a second component where more pleomorphic cells were associated with a prominent capillary pattern, and where neither fibrous septa nor tubules lined by cuboidal epithelium were present (Fig. 3).

There was considerable discussion as to the nature of this tumour, but the consensus was that it was an angiosarcoma; in a previous analysis of the CTR material, it was designated as such (Marsden and Steward, 1976). The prominent capillary pattern in the 'bone metastasising renal tumour of childhood' (Marsden et al., 1978) and the similarity between this tumour and the second component described in the present case raise the possibility that it may be an atypical variant of this tumour.

\section{CASE 6}

AKB (CTR 110/74) October 1974. A girl aged 5 months presented with a one-week history of haematuria and 'being off colour'. A large mass was palpable on the left side of the abdomen. Laparotomy was performed and showed almost complete replacement of the left kidney by white tumour. The capsule was penetrated by tumour and there were enlarged lymph nodes around the aorta above and below the renal vessels. Nephrectomy was attempted, but residual tumour was left in the abdomen. Chest $x$ rays and liver scans were normal. Radiotherapy was given. One month later bone destruction in the lower shaft of the right femur was noted. The infant developed chylous ascites and died a few days later. There was no necropsy.

\section{Pathology}

The kidney was almost entirely replaced by white tumour, $10 \times 7 \times 7 \mathrm{~cm}$, of variable consistency, and with areas of necrosis. A small portion of hydronephrotic kidney was present at one pole. Microscopically, the tumour had a prominent fibrous 


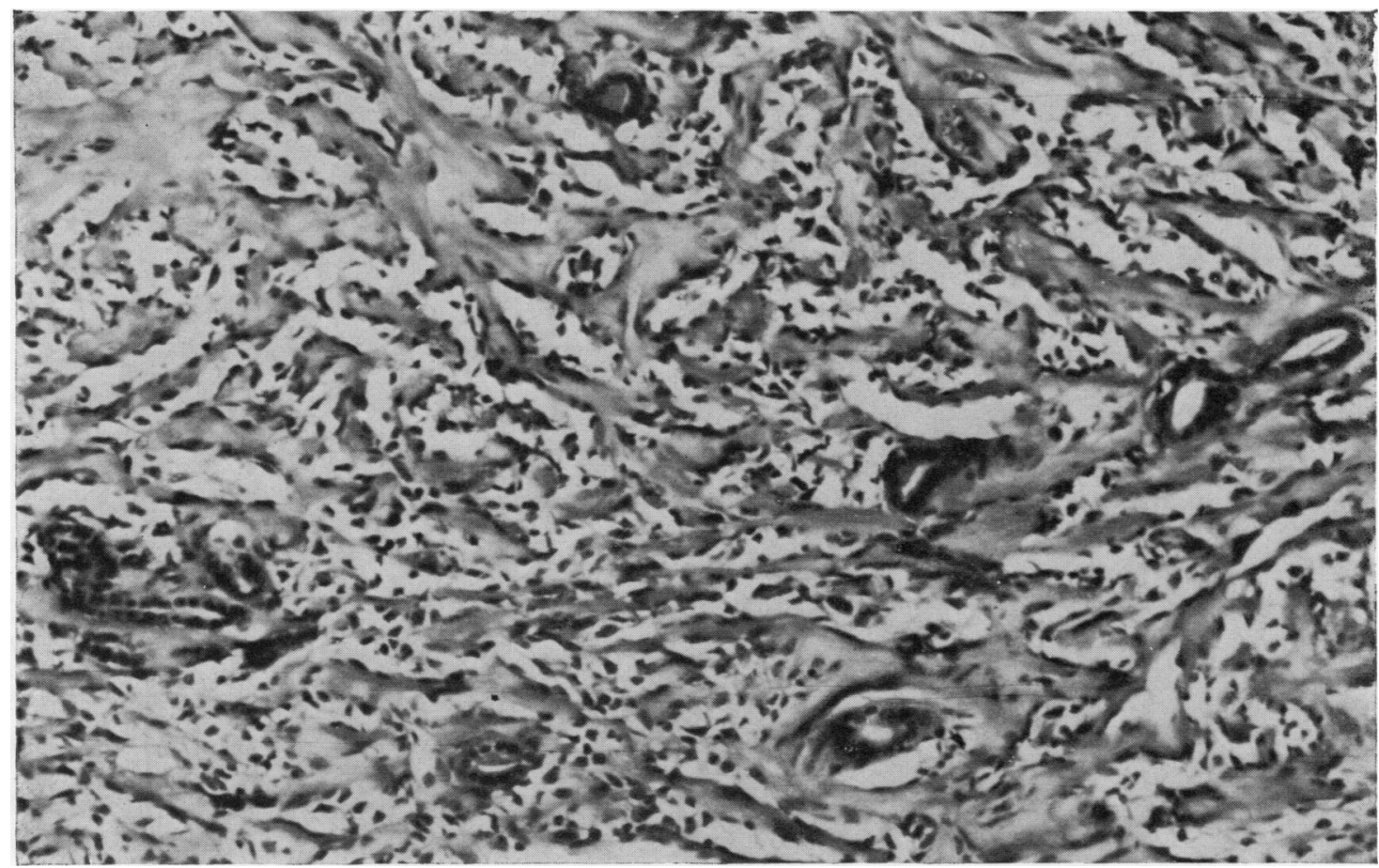

Fig. 2 Case 5. Atypical tumour with fibrous septa and clefts lined by small cells. Tubules lined by cuboidal epithelium are also present.

structure in which were embedded polygonal cells. The cell collections were variable in size, with single cells, small groups, and larger aggregates (Fig. 4). The overall appearances were uniform, although there was some variation in the density of the background fibrous stroma. Nucleoli were readily visible, but mitoses were very infrequent. Only occasional thin-walled capillaries were noted. Scanty tubules lined by cuboidal epithelium were present. The appearances were not regarded as those of a Wilms' tumour, and the neoplasm could not be placed into any existing classification of primary renal tumours of childhood.

\section{CASE 7}

AJH (CTR 73/55) September 1955. A boy aged 23 months whose parents had noted enlargement of his abdomen and pallor. He suddenly developed intermittent abdominal pain and vomiting. Examination of the abdomen showed a mass on the right side. At this stage the haemoglobin was $62 \%$, and the blood count was normal. Intravenous pyelography revealed enlargement of the right renal shadow and a mass in the upper pole of this kidney with distortion of the upper calyces and pelvis. $X$-rays of the skeleton were normal. At operation there was a purplish tumour mass arising from the right kidney, which extended through the peritoneum and which was adherent to the liver and transverse colon. Enlarged lymph nodes were present along the inferior vena cava, and there were peritoneal seedlings. Nephrectomy and excision of the tumour was carried out, but the wall of the latter ruptured during manipulation. Treatment with radiation baths to the abdomen was given. Four months later there was limitation of movement of the right arm, and $x$-rays showed a metastasis in the right humerus. Local radiotherapy was given. At this time there was also radiological evidence of spread to the mediastinum. A few weeks later a pathological fracture of the left femur developed, and there were enlarged lymph nodes in the left groin. There was also bony destruction in the left tibia. Abdominal masses developed with enlargement of lymph nodes in the right groin. The child died from bronchopneumonia after a clinical course of six months. The peripheral blood count was normal throughout. At necropsy there were masses in the right loin, pink tumour nodules up to $0.5 \mathrm{~cm}$ in diameter throughout the left kidney, enlarged mediastinal and abdominal para-aortic lymph nodes, and tumour deposits in the sternum and left femur. 


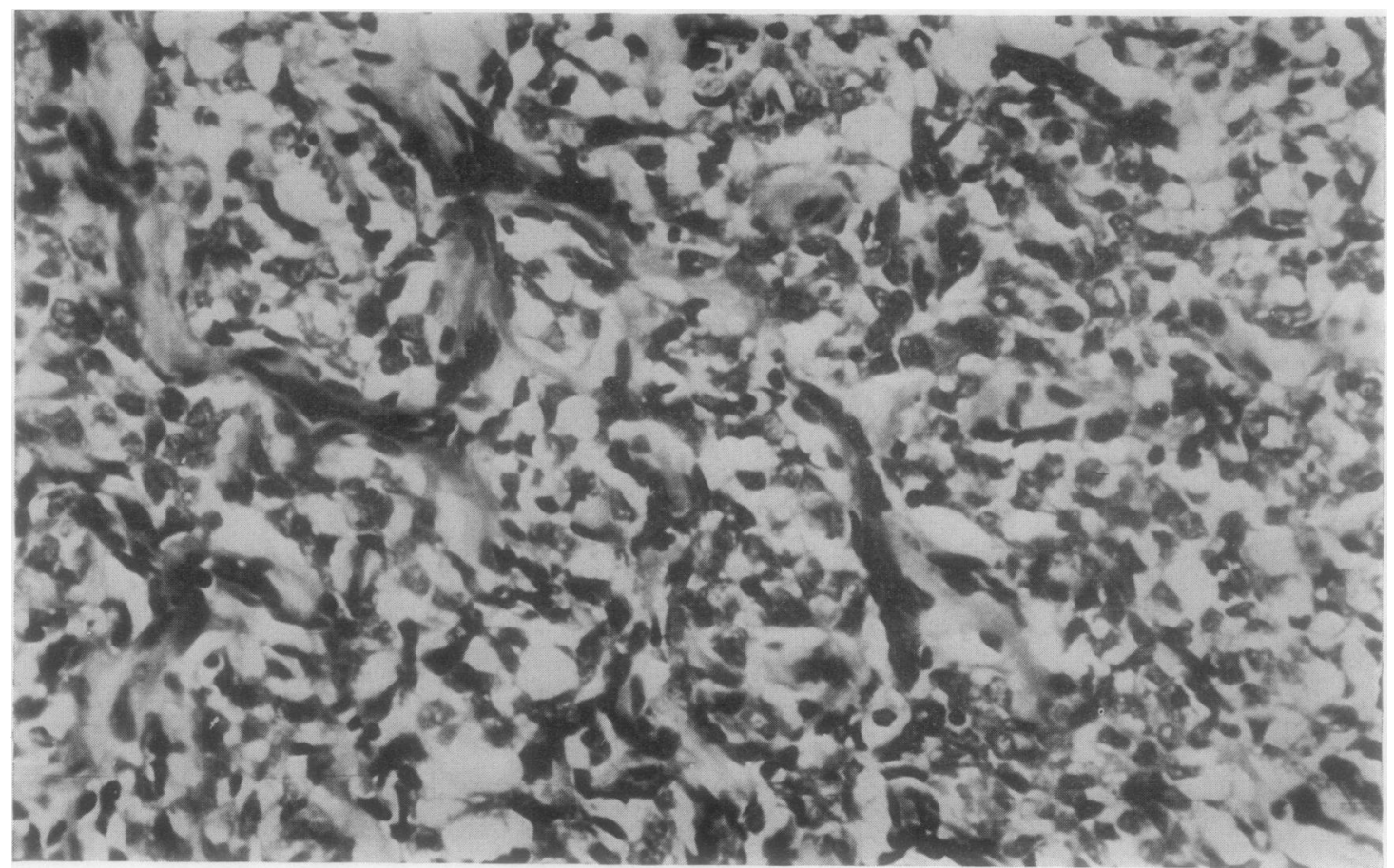

Fig. 3 Case 5. Minor component of the tumour shown in Fig. 2 with a prominent capillary pattern and cells showing more pleomorphism.

\section{Pathology}

Two-thirds of the right kidney was destroyed by a spherical mass of pink, friable, haemorrhagic, and necrotic tumour, $8 \mathrm{~cm}$ in maximum diameter, which extended into the renal pelvis. A second, rather smaller mass and an enlarged lymph node were attached to the kidney. Microscopy revealed the typical appearances of a lymphoblastic lymphosarcoma.

\section{Discussion}

Although there are several large series of Wilms' tumours in which bone metastases are briefly mentioned, there appear to be very few papers in which the histological appearances of the tumours which metastasised to bone have been described in detail; in most, no morphological descriptions are given.

Dean and Pack (1932) found bone metastases in two out of 16 cases of Wilms' tumour. Although they describe the pathology of their Wilms' tumours in general, they make no specific comments about the histology of the two which metastasised to bones.

Klapproth (1959) mentions bone metastases in one out of 36 cases where the diagnosis of Wilms' tumour was 'confirmed by histologic study'.

Hardwick and Stowens (1961), in a paper describing six histological types of Wilms' tumour from 84 cases, found one patient who subsequently developed bone metastases but do not state which type of tumour was found in this case.

Sukarochana and Kiesewetter (1966) noted that two out of their 62 children with Wilms' tumour developed bone metastases, but no mention of the histology in these cases is made.

Bannayan et al. (1971) found bone metastases in six children out of 55 with metastatic Wilms' tumour. They state that these patients had 'histologically proven Wilms' tumours', but no details are given.

Six of the 156 cases described by Cassady et al. (1973) had bones as the site of initial relapse, with or without involvement of lungs and/or liver. In this report 'the histologic diagnosis in all patients has

Aron (1974) noted that one patient out of 81 with the diagnosis of Wilms' tumour subsequently developed bone metastases. No histopathological details are given.

Similarly, Wolff et al. (1974) make no mention of been confirmed by the Pathology Department'. 


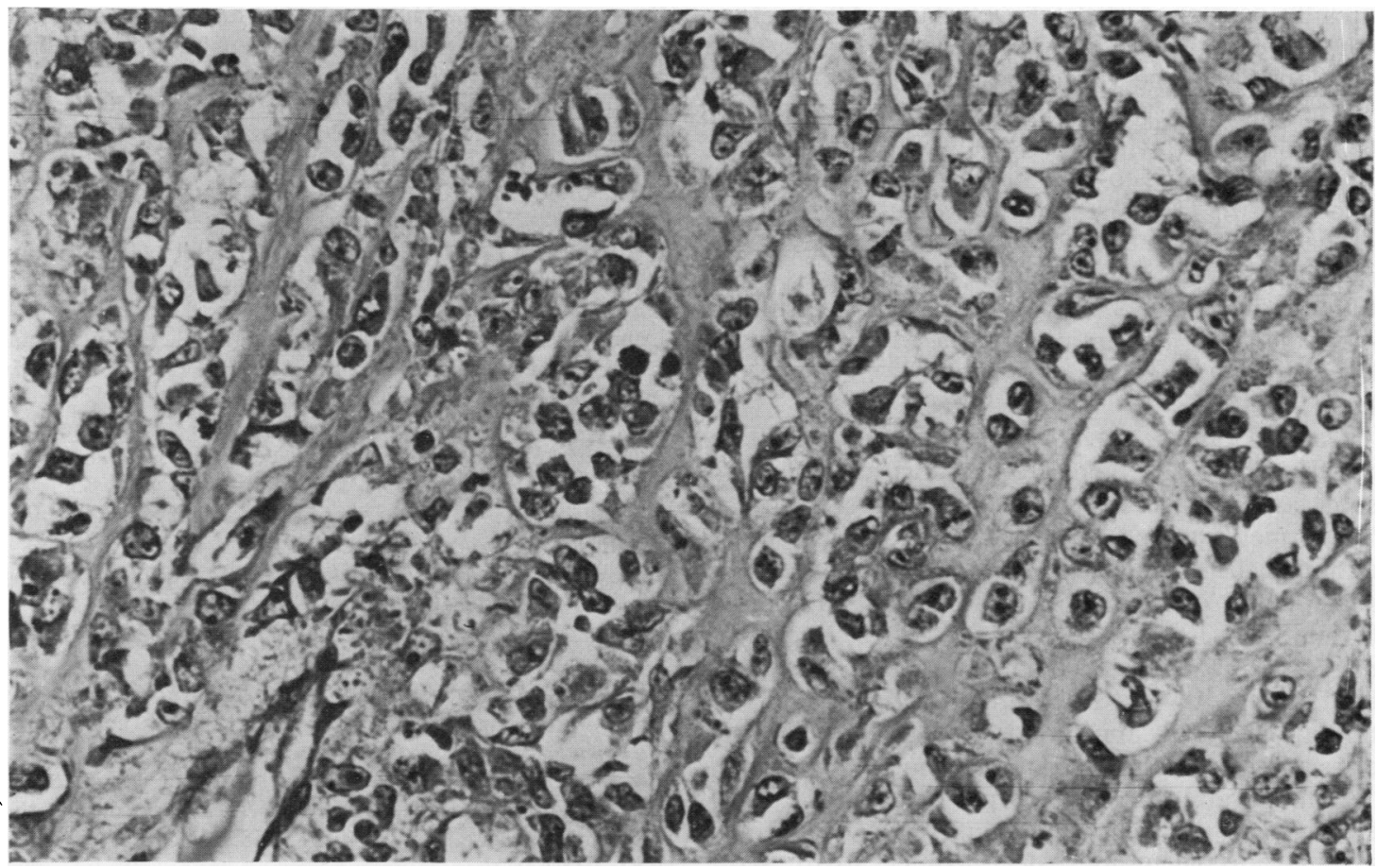

Fig. 4 Case 6. Atypical tumour with a prominent fibrous structure and embedded polygonal cells.

the pathology of their two patients with bone metastases out of 73 with Wilms' tumours.

Bond and Martin (1975) give clinical details of their two bone-metastasising Wilms' tumours out of 81 cases. In their case 1, 'histological study confirmed the diagnosis of Wilms' tumour', and in their case 2, 'histology of the renal mass showed an undifferentiated Wilms' tumour'.

Lemerle et al. (1976) analyse various histological features of Wilms' tumours but make no comment about the microscopic appearances of the tumours of the $8 \%$ of their patients at risk who developed bone metastases.

Single case reports of Wilms' tumours metastasising to uncommon sites, including bones, are given by Mintz (1934), Movassaghi et al. (1974), and Kumari (1976). Mintz (1934) describes the histological appearances of the tumour in his patient but provides no photomicrographs. He states that 'the tumour is composed of small, poorly differentiated spindle-shaped cells' with an occasional 'suggestion of acinar arrangements'. Movassaghi et al. (1974) state that 'microscopic examination of the (renal) tumour showed homogeneous primitive cells with some attempts at tubular formation', although the accompanying photomicrograph does not suggest a typical Wilms' tumour. Kumari (1976) states that the diagnosis of Wilms' tumour was confirmed pathologically, but no details are given.

The incidence for bone metastases in the published series of Wilms' tumours varies between $1.2 \%$ and $12.5 \%$. In a review of 1267 cases, Bond and Martin (1975) stated that 3.5\% developed metastases to bone. In this CTR series, only one typical Wilms' tumour out of 117 cases developed bone metastases (case 1). Five other cases in this series were initially regarded as nephroblastomata, but a review of the histology does not support this diagnosis (vide infra). There is limited information regarding the histopathological features of the published cases, and it is possible that some are not Wilms' tumours.

Skeletal deposits from primary renal carcinoma (hypernephroma) in adults are fairly common-in necropsy series they are seen in approximately onethird of cases (Lucké and Schlumberger, 1957; Thackray, 1964; Robbins 1974). In clinical series from adults, the incidence of bone metastases from hypernephroma has been $3 \%$ (Judd and Hand, 1929), $4.2 \%$ (Cook et al., 1975), $13 \%$ (Ochsner et al., 1973), and $18.9 \%$ (Nalle, 1947). Aron and Gross (1969) reviewed 30 cases of renal adenocarcinoma in infancy and childhood and found that two of these subse- 
quently developed skeletal metastases. Of the four children in the CTR with hypernephroma, one developed bone metastases (case 2).

The concept of a bone-metastasising renal tumour of childhood, which merits separation from nephroblastoma, appears to have been first propounded by Kidd (1970). Two cases in this present series (3 and 4) have, together with several other cases, been included as examples of a 'bone metastasising renal tumour of childhood' in previous reports in which more detailed descriptions of these tumours have been given (Marsden et al., 1978; Marsden and Lawler, 1978).

Cases 5 and 6 are atypical and are difficult to classify. In case 5 , there are histological features in some areas which are similar to those seen in the 'bone metastasising renal tumour of childhood', although the overall prominent vascular component suggested a diagnosis of angiosarcoma. Capillary formation is, however, a striking feature of the "bone metastasising renal tumour of childhood'. This capillary pattern is not a feature of case 6 , and the tumour did not appear to fit into any existing classification of primary renal tumour of childhood.

Lymphosarcoma rarely presents with renal enlargement sufficient to be confused clinically with a primary renal tumour (de Lorrimer, 1976). Scott (1954) described two children, one with Hodgkin's disease and one with lymphosarcoma, who presented in this way. Three adults with lymphosarcomas presenting as renal tumours were reported by Gibson (1948). Case 7 in this present series also showed similar features.

\section{Conclusions}

Spread to bone is uncommon in children presenting with renal tumours. In this series, only one Wilms' tumour behaved in this way, and four out of the six primary renal tumours with bone metastases were found to be atypical on microscopy. Particular attention should be paid to the histological features of renal tumours which subsequently metastasise to bones.

HBM is in receipt of a grant from The Children's Research Fund, 6, Castle Street, Liverpool.

\section{References}

Aron, B. S. (1974). Wilm's tumor-a clinical study of 81 patients. Cancer, 33, 637-646.

Aron, B. S., and Gross, M. (1969). Renal adenocarcinoma in infancy and childhood: evaluation of therapy and prognosis. Journal of Urology, 102, 497-503.
Bannayan, G. A., Huvos, A. G., and D'Angio, G. J. (1971). Effect of irradiation on the maturation of Wilms' tumour. Cancer, 27, 812-818.

Bond, J. V., and Martin, E. C. (1975). Bone metastases in Wilms' tumour. Clinical Radiology, 26, 103-106.

Cassady, J. R., Tefft, M., Filler, R. M., Jaffe, N., and Hellman, S. (1973). Considerations in the radiation therapy of Wilms' tumor. Cancer, 32, 598-608.

Cook, S. A., Tarar, R. A., and Lalli, A. F. (1975). Bony metastasis in renal cell carcinoma. Cleveland Clinical Quarterly, 42, 263-265.

Dean, A. L., Jr., and Pack, G. T. (1932). Embryonal adenosarcoma of the kidney. Journal of the American Medical Association, 98, 10-17.

de Lorimer, A. A. (1976). Tumours of the kidney. In Clinical Paediatric Nephrology, edited by E. Lieberman, pp. 469-507. Lippincott, Philadelphia.

Gibson, T. E. (1948). Lymphosarcoma of the kidney. Journal of Urology, 60, 838-854.

Hardwick, D. F., and Stowens, D. (1961). Wilms tumors. Journal of Urology, 85, 903-910.

Judd, E. S., and Hand, J. R. (1929). Hypernephroma. Journal of Urology, 22, 10-21.

Kidd, J. M. (1970). Exclusion of certain renal neoplasms from the category of Wilms' tumor (abstract). American Journal of Pathology, 59, 16a.

Klapproth, H. J. (1959). Wilms' tumor: a report of 45 cases and an analysis of 1351 cases reported in the world literature from 1940 to 1958. Journal of Urology, 81, 633-648.

Kumari, S. (1976). Wilms' tumour with bony metastases. Southern Medical Journal, 69, 812-813.

Lemerle, J., Tournade, M. F., Gerard-Marchant, R., Flamant, R., Sarrazin, D., Flamant, F., Lemerle, M., Jundt, S., Zucker, J. M., and Schweisguth, O. (1976). Wilms' tumor: natural history and prognostic factors. Cancer, 37, 2557-2566.

Lucké, B., and Schlumberger, H. G. (1957). Tumors of the Kidney, Renal Pelvis and Ureter. (Atlas of Tumor Pathology, Section VIII, Fascicle 30), pp. 42-78. Armed Forces Institute of Pathology, Washington.

Marsden, H. B., and Lawler, W. (1978). Bone-metastasizing renal tumour of childhood. British Journal of Cancer, 38, 437-441.

Marsden, H. B., Lawler, W., and Kumar, P. M. (1978). Bone metastasising renal tumour of childhood. Morphological and clinical features, and differences from Wilms' tumor. Cancer, 42, 1922-1928.

Marsden, H. B., and Steward, J. K. (1976). Tumours in Children, 2nd edition, p. 359. Springer, Berlin.

Mintz, E. R. (1934). Embryoma of the kidney in an infant with osseous metastases. Report of a case. Journal of Urology, 31, 79-86.

Movassaghi, N., Leikin, S., and Chandra, R. (1974). Wilms' tumor metastasis to uncommon sites. Journal of Paediatrics, 84, 416-417.

Nalle, B. C., Jr. (1947). Distant metastases of 58 renal neoplasms: a case report of secondary metastatic pulsations from a renal tur.or. Journal of Urology, 57, 662-668.

Ochsner, M. G., Brannan, W., Pond, H. S., and Goodier, E. H. (1973). Renal cell carcinoma: a review of 26 
years of experience at the Ochsner Clinic. Journal of Urology, 110, 643-646.

Robbins, S. L. (1974). Pathologic Basis of Disease, p. 1142, Saunders, Philadelphia.

Scott, L. S. (1954). Renal tumours in childhood. Glasgow Medical Journal, 35, 33-45.

Sukarochana, K., and Kiesewetter, W. B. (1966). Wilms' tumor: factors influencing long-term survival. Journal of Paediatrics, 69, 747-752.

Thackray, A. C. (1964). The pathology and spread of renal adenocarcinoma. In Tumours of the Kidney and Ureter, (Neoplastic Disease at Various Sites, Volume
5), edited by E. Riches, pp. 72-86. Livingstone, Edinburgh and London.

Wolff, J. A., D’Angio, G., Hartmann, J . Krivit, W., and Newton, W. A. (1974). Long term evaluation of single versus multiple courses of Actinomycin D therapy of Wilms' tumour. New England Journal of Medicine, 290, 84-86.

Requests for reprints to: Dr W. Lawler, Department of Pathology, Stopford Building, The University, Manchester M13 9PT, UK.

\section{Reports and Bulletins prepared by the Association of Clinical Biochemists}

The following reports and bulletins are published by the Association of Clinical Biochemists. They may be obtained from The Publishing Department, British Medical Journal (ACB Technical Bulletins), B.M.A. House, Tavistock Square, London WC1H 9JR. Overseas readers should remit by British Postal or Money Order.

SCIENTIFIC REVIEWS (price $£ 1 \cdot 00 / \$ 2.00$ each)

1 The assessment of thyroid function March 1971

F. V. FLYNN and J. R. HOBBS

2 Renal function tests suitable for clinical practice January 1972 F. L. MTTCHELL, N. VEALL, and R. W. E. WATTS

3 Biochemical tests for the assessment of fetoplacental function May 1975 C. E. WILDE and R. E. OAKEY

4 Test of exocrine pancreatic function March 1977 A. H. GOWENLOCK

5. Assay of cholinesterase in clinical chemistry March 1979 ELSIE SILK, J. KING, and MARY WHITTAKER

TECHNICAL BULLETINS (price $£ 1 \cdot 00 / \$ 2.00$ each)

22 Bilirubin standards and the determination of bilirubin by manual and technicon AutoAnalyzer methods January 1971 BARBARA BILLING, RUTH HASLAM, and N. WALD

23 Interchangeable cells for spectrophotometers and fluorimeters September 1971 s. S. BROWN and A. H. GOWENLOCK

24 Simple tests to detect poisons March 1972 B. w. MEADE et al.

25 Blood gas analysers May 1972 K. DIxON

26 Kits for enzyme activity determination September 1972 S. B. ROSALKI and D. TARLOW

27 Assessment of pumps suitable for incorporation into existing continuous flow analytical systems November 1972 A. FLECK et al.
28 Routine clinical measurements of transferrin in human serum September 1973 K. DIXON

29 Control materials for clinical biochemistry (5th edition) September 1973 J. F. STEVENS

30 Notes on the quality of performance of serum cholesterol assays September 1973 S. S. BROWN

31 Determination of uric acid in blood and in urine July 1974 R. W. E. WATTS

32 A survey of amino acid analysers readily available in the United Kingdom September 1974 J. E. CARLYLE and P. PURKISS

33 Definitions of some words and terms used in automated analysis November 1974 A. FLECK, R. ROBINSON, S. S. BROWN, and J. R. HOBBS

34 Measurement of albumin in the sera of patients January 1975 LINDA SLATER, P. M. CARTER, and J. R. HOBBS

35 Investigation of the validity of temperature correction factors for serum aspartate and alanine transaminases March 1975 S. B. ROSALKI et al.

36 Factors influencing the assay of creatinine November 1975 J. G. H. COOK

37 A survey of enzyme reaction rate analysers readily available in the United Kingdom July 1977 R. A. SAUNDERS and R. F. BURNS

38 Transport of specimens for clinical chemistry analysis November 1977 P. WILDING, J. F. ZILVA, and C. E. WILDE

39 A scheme for the evaluation of diagnostic kits May 1978 P. H. LLOYD 